\title{
Column Splice Fracture Effects on the Seismic Performance of Steel Moment FRAMES
}

\author{
Kimberly Stillmaker ${ }^{1}$, Xai Lao ${ }^{2}$, Carmine Galasso ${ }^{3}$ and Amit Kanvinde ${ }^{4}$ \\ ${ }^{1}$ Assistant Professor, Department of Civil and Geomatics Engineering, California State \\ University, Fresno, CA 93740, USA \\ ${ }^{2}$ Graduate Research Assistant, Department of Civil and Environmental Engineering, University \\ of California, Davis, CA 95616, USA \\ ${ }^{3}$ Lecturer, Department of Civil, Environmental \& Geomatic Engineering and Institute for Risk \& \\ Disaster Reduction, University College London, UK \\ ${ }^{4}$ Professor, Department of Civil and Environmental Engineering, University of California, \\ Davis, CA 95616, USA
}

\section{AbSTract}

The influence of welded column splice fracture on the seismic response of steel moment frames is examined. The study is motivated by pre-Northridge moment frames with welded column splices with crack-like flaws that are highly vulnerable to fracture. Costly retrofit strategies to repair these splices are usually intentioned to preclude splice fracture, without an explicit examination of its effects on global response. This study simulates post-fracture response of splices through a new material model, which is informed by fracture-mechanics based estimates of splice strength, and reproduces phenomena such as gapping and re-seating that occurs in the splices after fracture. Nonlinear response history simulations (incorporating this model) are used to examine the response of 4- and 20- story moment frames. The simulations, using 100 ground motions, and reflecting key aspects of nonlinear response are conducted within a Performance Based Earthquake Engineering (PBEE) framework, to examine global and local structural response in a probabilistic sense. The simulations indicate that neither the collapse potential nor building deformations are significantly affected by splice fracture when compared to benchmark simulations without fracture. This is attributed to a combination of phenomena; these include the mobilization of building rocking due to splice fracture, and the tendency of fractures to cascade upwards through individual columns rather than across a story. The results suggest that splice fracture may not necessarily trigger structural collapse, and retrofit strategies that consider global, rather than local response may be more cost effective. Limitations of the study are outlined.

\section{Keywords: Steel Connections; Fracture; Performance Assessment; Moment Frames}


INTRODUCTION AND BACKGROUND

Brittle fractures observed during the M6.7 1994 Northridge earthquake instigated extensive examination (e.g., the SAC Joint Venture $(1996,1995)$ ) of welded beam-column connections in Steel Moment Resisting Frames (SMRFs). These studies determined that pre-existing flaws, in conjunction with low toughness materials and poor connection design were responsible for these fractures. Ultimately, these studies led to stringent material toughness and detailing requirements as well as guidelines for upgrading vulnerable connections in SMRFs and other structural systems (AISC, 2010). Although beam-column connections were the primary focus of post-Northridge investigations and subsequent retrofit, other connections, such as welded column splices (WCSs) with Partial Joint Penetration (PJP) welds were identified to be vulnerable as well (CUREe, 1995). Figure 1 schematically illustrates a pre-Northridge welded column splice detail. Referring to the Figure, these connections featured low flange weld penetrations, i.e., weld throat between $40 \%$ $60 \%$ of the thinner flange thickness (Nudel et al., 2015). Moreover, the Charpy V Notch (CVN) energy of weld filler materials in these connections was in the range of 5-10 ft-lbs (Chi et al., 2000); this is significantly lower than the post-Northridge requirements (AISC, 2010) that mandate

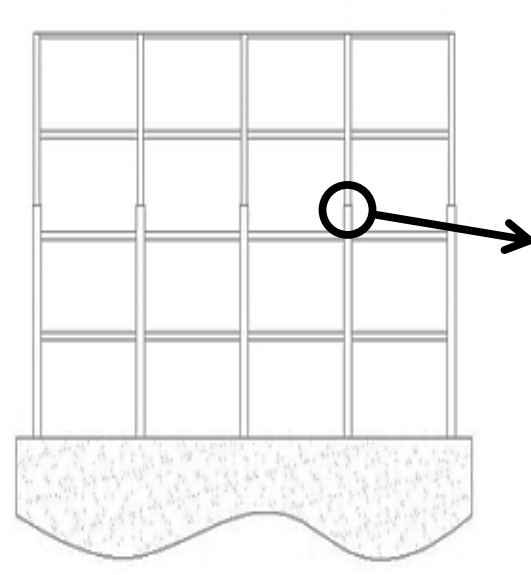

Steel Moment Resisting Frame

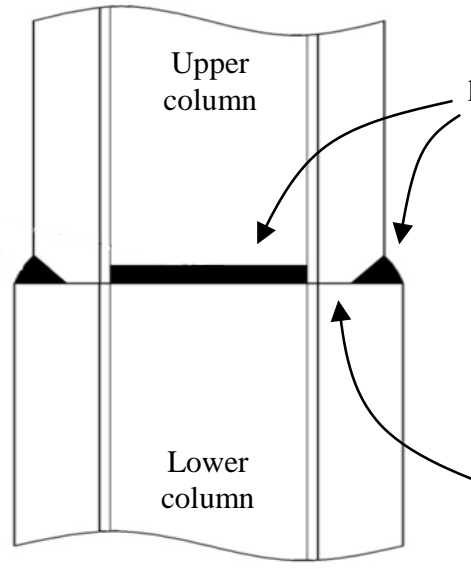

Pre-Northridge splice detail elevation
PJP Welds with 40-60\% penetration for both flange and web

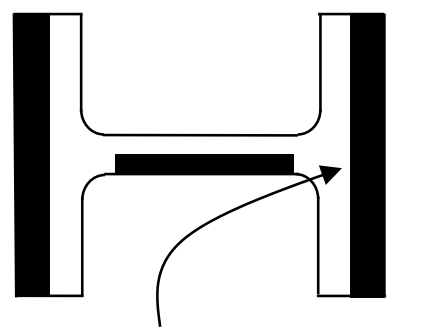

Unfused weld root acting as sharp crack

Splice cross-section through upper column

Figure 1: Partial Joint Penetration (PJP) welds in pre-Northridge Steel Moment Resisting Frame 
weld filler metal CVN toughness greater than $20 \mathrm{ft}-\mathrm{lb}$ at $0^{0} \mathrm{~F}$. The lack of full penetration in these

51 splices produces a crack-like flaw (a stress raiser) that renders them susceptible to fracture, and

52 significantly lowers their strength. To address this, the post-Northridge design provisions (AISC,

53 2010) also mandate the use of Complete Joint Penetration (CJP) welds in welded column splice

54 connections, eliminating the crack-like flaw. The fracture vulnerability of pre-Northridge PJP

55 splices (implied by the new design provisions) is confirmed by experiments (Bruneau and Mahin,

56 1991), and finite element simulations by Nuttayasakul (2000), and more recently by Stillmaker et

57 al. (2016). These studies indicate that pre-Northridge splices have flange fracture strengths in the

58 range of $15-25 \mathrm{ksi}$ (in contrast to the expectation of flange yielding, i.e., $\sim 55 \mathrm{ksi}$, as implied by the

59 current provisions - AISC, 2010).

60 The design provisions (both pre- and post-Northridge) require welded splice connections to be

61 located near mid story height, where moment demands are anticipated to be low under first-mode

62 building response. However, nonlinear time history simulations (Shaw et al., 2015; Shen et al.,

63 2010) indicate that moment and axial force demands at these locations (especially in high-rise

64 frames) are significant, such that the peak tensile stresses at the splices approach the yield strength

65 of the column flanges. This is due to higher mode response (which causes single curvature bending

66 of the columns) and column tension from overturning effects that are dominant in high-rise frames.

67 Galasso et al., (2015) conducted probabilistic risk analysis of splice fracture within a Performance

68 Based Earthquake Engineering (PBEE) based framework. This analysis indicates that high tensile

69 stress demands and low strengths of pre-Northridge WCSs result in a high risk of fracture. More

70 specifically, for the 20-story building considered by Galasso et al., (2015), the return period for

71 splice fracture was determined to be as low as 87 years. This may be considered unacceptably

72 high. These observations (and the observation that many existing buildings on the West Coast of 
73 the United States still have unrepaired pre-Northridge details with PJP welds) have resulted in

74 increased initiative to retrofit these splices in existing buildings (Nudel et al., 2015) to achieve

75 conformance with current design and safety standards (AISC, 2010). Retrofit of these splices

76 (which typically involves replacing the PJP welds with CJP welds) is costly, since the columns are

77 in the gravity load path and often cannot be conveniently accessed in operational buildings. The

78 high likelihood of fracture (as suggested by these studies) implies that a large majority of splices

79 in mid- to high-rise pre-Northridge SMRFs may require retrofit for compliance with current

80 performance standards. Although such a retrofit strategy is well-intentioned, it assumes that

81 fracture in any splice is unacceptable and that splice fracture will inevitably lead to loss of safety

82 or collapse. While this may be the case for some configurations and ground motions, none of the

83 aforementioned studies have examined the effect of splice fracture on frame response; specifically,

84 whether the loss of one splice triggers a cascading effect leading to loss of strength capacity and

85 collapse, or alternatively, whether fracturing splices alter the dynamic response of the system (e.g.,

86 through period elongation or frame rocking) such that post-fracture response is less adverse.

87 Qualitative, physics-based arguments may be made in support of either response mode (or an 88 interaction of the two). However, a rigorous characterization of building response that quantifies

89 the risk of structural (rather than connection) limit states in a probabilistic manner is necessary to 90 fully elucidate the tradeoffs between the cost and benefits of retrofit.

91 It is interesting to note here that a key shortcoming of first-generation PBEE documents (Applied

92 Technology Council, 1997; ASCE, 2006) is cited as their reliance on component limit states as 93 indicators of system response (Applied Technology Council, 2006). The notion of assuming splice 94 failure as an indicator of structural failure and mitigation strategies that consider connection failure 
95 in isolation may be criticized similarly. With this background, the specific objectives of this study

96 are:

97 1. To examine the effect of splice fractures on the seismic response (including story deformations

98 and collapse) of generic SMRF buildings representative of pre-Northridge construction, in a probabilistic, performance-based engineering framework consistent with modern

2. To generate fundamental insights into physical modes of structural response that follow splice fracture to inform engineering intuition and retrofit strategies.

3. Based on the above, to provide general commentary regarding the retrofit of pre-Northridge SMRF buildings that are subject to welded column splice fracture. (NLRHA) of two generic (4- and 20- story) SMRFs subjected to a suite of ground motions. The simulations include: (1) frames with non-fracturing splices (representative of a retrofitted frame) and (2) frames with simulated splice fracture. A distinguishing feature of the NLRHA is the high-

110 fidelity simulation of splice fracture; this has two aspects: (1) it is based on previous experimental 111 and fracture mechanics studies by the authors (Shaw et al., 2015; Stillmaker et al., 2016), such that 112 the fracture stress is simulated with accuracy, and (2) post-fracture phenomena including loss of 113 tensile capacity and subsequent gapping and closure are simulated in a rigorous manner.

114 The next section summarizes pertinent aspects of the archetype frames and the NLRHA models, 115 including the methodology used to simulate fracture. This is followed by a discussion of the 116 probabilistic framework for performance assessment (within which the NLRHA models are used) 
117 and the simulation strategy to interrogate various scenarios in support of the objectives above.

118 Results of the simulations are then discussed, along with implications for design and retrofit, and

119 limitations of the study.

120

121

122

123

124

125

126

127

128

129

130

131

132

133

134

135

136

\section{ARChetyPe Frames and Simulation Model}

As discussed in the introduction, two generic frames (4- and 20- story) were examined in this study. These frames are schematically illustrated in Figure 2.
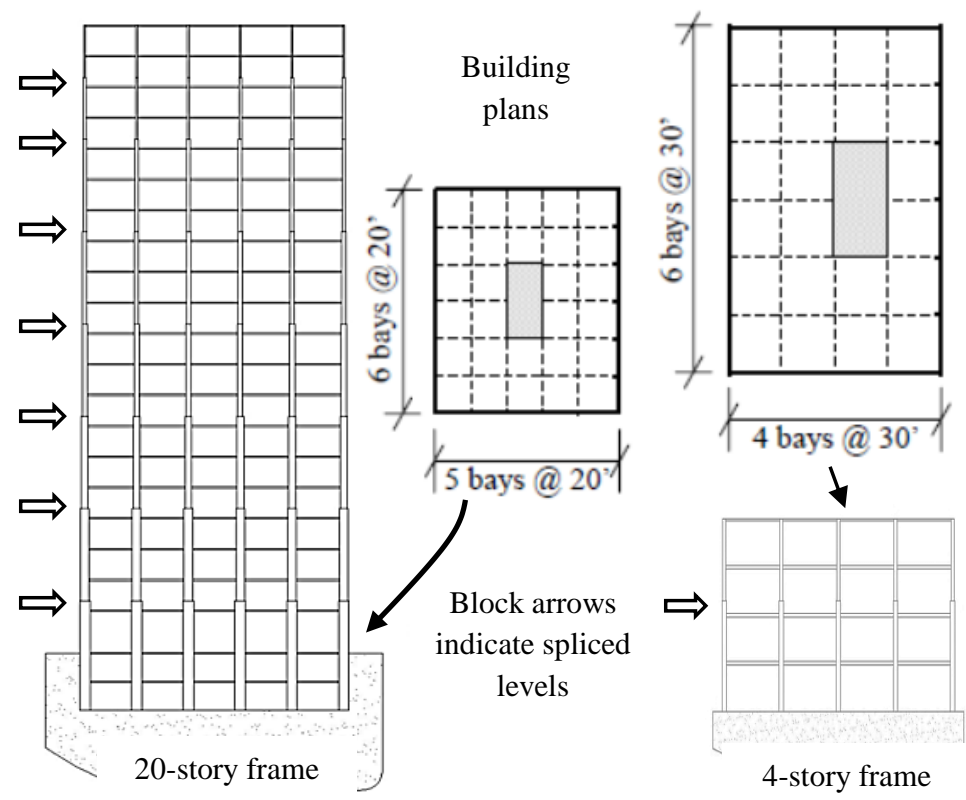

Figure 2: Moment frames considered in this study - overall geometry, elevation, and building plans

These structures are identical to those used by Shen et al. (2010), Shaw et al.(2015), and subsequently Galasso et al. (2015) for demand assessment in WCSs. The frames are geometrically similar to those in model buildings studied in the SAC Steel Project (Gupta and Krawinkler, 1999), with some modifications. The extensive prior study on these buildings provides an opportunity to evaluate the effects of splice fracture against benchmark response data that does not simulate splice fracture. The frames conform to the loadings of ASCE 7-05 (ASCE, 2005) and the design provisions of the AISC Seismic Provisions, i.e., AISC 341-10, implying that they may be 
137 considered "post-Northridge" in terms of their structural design. However, as noted by Gupta and 138 Krawinkler (1999), pre- and post- Northridge frames are similar in terms of global response and 139 member force demands, assuming that: (1) these frames have been constructed in the 1973-1994 140 era, and benefit from Strong-Column-Weak-Beam (SCWB) considerations that were introduced 141 during the 1970s following soft-story collapses observed during the 1971 San Fernando 142 earthquake, and (2) beam-column connections do not fracture due to retrofit. While these 143 assumptions represent response of a large portion of the building stock, their limitations are 144 discussed during interpretation of the results. The frames were designed for seismicity consistent 145 with the Los Angeles, California region, and typical gravity loading of an office building. Firm 146 soil conditions (NEHRP - National Earthquake Hazards Reduction Program - Site Class D) were 147 assumed in design. Shaw (2013) outlines design assumptions, loadings, and other aspects of the 148 frames including specific member sizes in greater detail.

149 The splices were located 4 feet from the lower story beam in each spliced story. This is the 150 minimum distance required as per AISC 341-10 with the presumption that first mode response 151 results in maximum moments at the ends of the column (with a point of inflection at mid-story 152 height). Providing column splices at the minimum required distance represents the least 153 conservative scenario within current design standards. Elastic modal analysis indicated that the 154 fundamental periods for the 4- and 20- story frames were 0.94 and 2.37 seconds, respectively. For 155 both frames, simulation models were developed in OpenSEES (Mazzoni et al., 2009), which 156 allows for the simulation of highly nonlinear structural response. For illustration, Figure 3 157 schematically shows the OpenSEES model for the 4-story frame; the model for the 20-story frame 158 employs similar modeling assumptions. Referring to Figure 3, the main modeling assumptions and 159 features are now summarized: 
1. All beams and columns were simulated as force-based fiber elements (Spacone et al., 1996), with the objective of simulating axial force and moment interaction as well as spread of plasticity through the member length. To appropriately represent curvature gradients, approximately 5 elements were used per column, and approximately 1 element were used per beam. Additional elements were inserted to represent the RBS details in the beams. Each element had 5 Gauss integration points along its length. Figure 3 also shows typical discretization of a cross-section with fibers; between 64 and 192 fibers were used for various cross sections to capture gradients across the cross-section.

2. Figure 3 also schematically illustrates the uniaxial material properties used to represent beam and column sections. Referring to the figure, a kinematic hardening model was used to represent cyclic response of the steel material, with elastic modulus $E=29,000 \mathrm{ksi}$, a hardening slope $5 \%$ of the elastic modulus, and yield stress $\sigma_{Y}=55 \mathrm{ksi}$. These values are consistent with previous simulations by the authors (Galasso et al., 2015), as well as experimental data (Kanvinde and Deierlein, 2004; Ricles et al., 2004).

3. Finite joint size was simulated using rigid offsets, although panel zone flexibility (or yielding) was not explicitly simulated.

4. Both member $(P-\delta)$ and story $(P-\Delta)$ effects were explicitly simulated through the use of geometric transformations. A leaning column (also shown in Figure 3) was used to simulate the destabilizing effect of the vertical loads on the gravity frames. The lateral resistance of the gravity frames themselves was discounted - a conservative assumption from the standpoint of structural performance. 


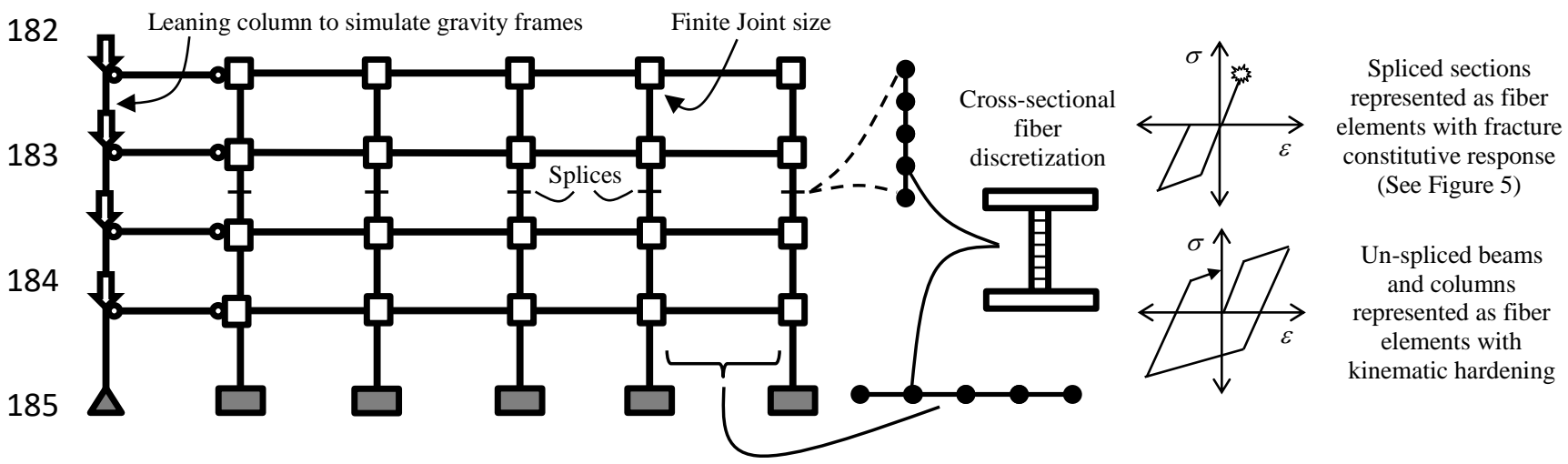

Figure 3: Schematic illustration frame simulation model used in NLRHA, shown for the 4story frame

187 In view of the major objectives of this study, splice fracture was simulated rigorously within the 188 constraints of frame-based analysis. A review of prior experimental (Bruneau and Mahin, 1991;

189 Shaw et al., 2015) and computational fracture mechanics (Stillmaker et al., 2016) studies on PJP 190 WCSs informs this approach. Specifically, the following observations from these prior studies are 191 relevant:

192 1. Fracture originates at the root of the weld, i.e., at the tip of the crack like flaw created by the unfused region within the flange and instantaneously severs the flange (see Figure 4 below -
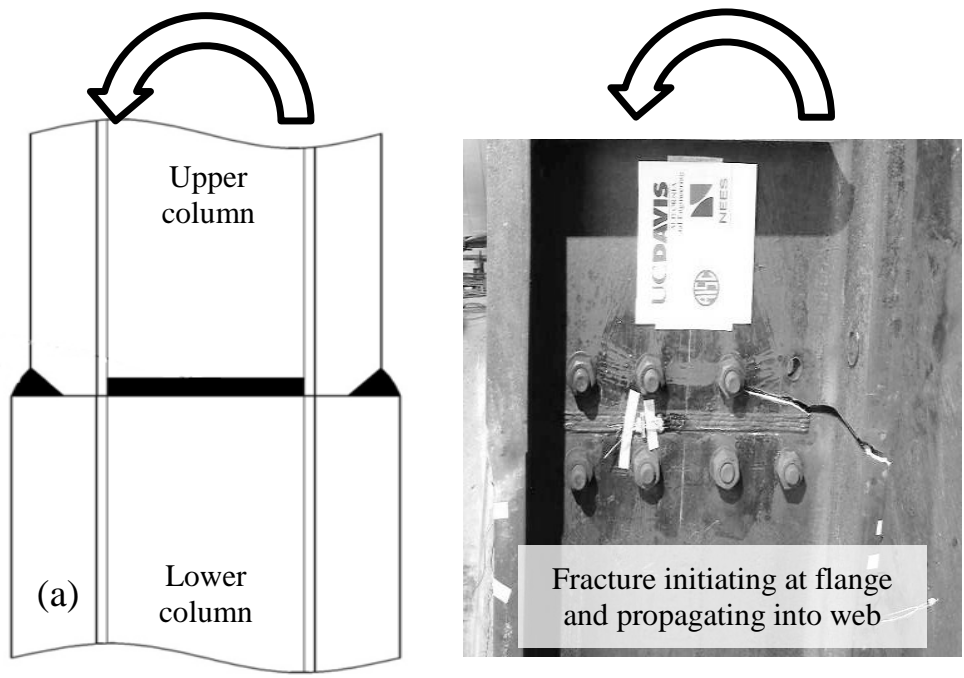

Figure 4: Fracture propagation in welded column splice (from Shaw et al., 2015) 
from the tests of Shaw et al., 2015). The fracture usually propagates through a significant portion of the web before being arrested. Although varying degrees of localized yielding are observed in the splice details (depending on the degree of weld penetration and flange sizes), fracture may be considered stress controlled, such that a flange stress may be uniquely assigned to the occurrence of fracture. Moreover, the fracture may also be considered independent of

2. Further to the point above, this critical stress may be determined through classical fracture mechanics theory (Anderson, 1995), applied through finite element simulations to the splice connection of interest and the attendant configurational parameters such as weld penetration, flange thickness, and material toughness. A comprehensive overview of such simulations, as well as simplified analytical equations to predict initiation of fracture based on splice configuration, may be found in Stillmaker et al., (2016).

3. All the experiments in the studies cited were terminated upon splice fracture, and further reversed cycles were not applied. Consequently, the effects of column re-seating (and closure of fractured crack faces) on a subsequent load reversal during seismic loading have not been observed experimentally. In this study, it is assumed that the column re-seats in compression; implications of this assumptions are discussed during the interpretation of results.

212 Based on the above observations, each spliced section is simulated as a beam-column element of 213 a small length, i.e., 2 inches. The length of this element is not germane to the simulation, except 214 for representing a segment of the member over which moment gradient is low, such that a stress215 based fracture criterion may be applied to this element. Within this cross-section, all fibers are 
216 assigned a constitutive model that is able to replicate the response associated with fracture. The

217 primary characteristics of this model are as follows:

218 1. Elastic response in tension until a fracture stress, $\sigma_{\text {fracture }}$, is reached. The fracture stress is

219 determined for each fiber within the spliced cross-section depending on the degree of weld 220 penetration and the thicknesses of the flanges or webs being connected. Specifically, $\sigma_{\text {fracture }}$

221 was determined following the work of Stillmaker et al., (2016), either from results of finite 222 element based fracture simulations (as in the case of the 4-story frame) or per Equation 1 223 below:

$$
\sigma_{\text {fracture }}=\frac{K_{I C}}{\sqrt{\pi \times(\eta / 2 \xi) \times t_{u}}} \times \frac{1}{f(\eta, \xi)}
$$
connections (Chi et al., 2000) converted to a stress intensity factor conservatively using the relation proposed by Barsom (1975). The variable $\eta=a / t_{l}$ represents the percentage of crack $f(\eta, \xi)$ represents a polynomial function with coefficients regressed to optimize agreement with experimental results (Shaw et al., 2015) and finite element based fracture mechanics simulations (Stillmaker et al., 2016). Equation (1) is specifically customized to the geometry of the PJP splice details, and is able to characterize the effect of crack tip yielding. For the various splices in the frames considered in this study, $\sigma_{\text {fracture }}$ is in the range of 8.6 -25.7 ksi. 
235 2. After $\sigma_{\text {fracture }}$ is reached, the material loses all stress capacity in tension. Note that this is 236 different from simulating fracture through a negative slope in the constitutive response of the 237 fiber construct, which would produce mesh dependency of the solution (e.g., see Wu and 238 Wang(2010)), and also result in energy dissipation, which is spurious and physically 239 inconsistent with brittle fracture.

240 3. In compression, the model is elastic up to the expected yield strength, and then hardens 241 indefinitely with a slope $5 \%$ of the elastic modulus, assuming that the column effectively re242 seats, and compressive behavior is unaffected by tension fracture.

243 A constitutive model to reflect the above response is not available in OpenSEES. Consequently, 244 the response was constructed by arranging pre-implemented material models in "series" or 245 "parallel" fashion, as indicated schematically in Figure 5a. The resulting cyclic response is 246 illustrated in Figure 5b. The points marked numerically (i.e., 1,2,3,...) in Figure 5b show the 247 sequential evolution of the stress-strain history, showing initial elastic loading 0-1, unloading and 248 compressive loading and yielding 2-3-4, and fracture upon reloading in the tensile direction at 5. 249 Referring to the figure, this manner of simulating fracture is able to (1) simulate "snap-back," 250 wherein the strain returns elastically to zero after fracture, and then increases back up to the applied 251 strain 5-6-7, eliminating spurious dissipation, and (2) eliminate mesh sensitivity, both of which are 252 problematic if fracture is simulated through a steep negative slope, i.e. following the path indicated 253 by $5-6$ ' -7 , as is often done. Subsequent to fracture, the material has no strength in tension, although 254 it maintains strength in compression, see points 7-8-9-10. 

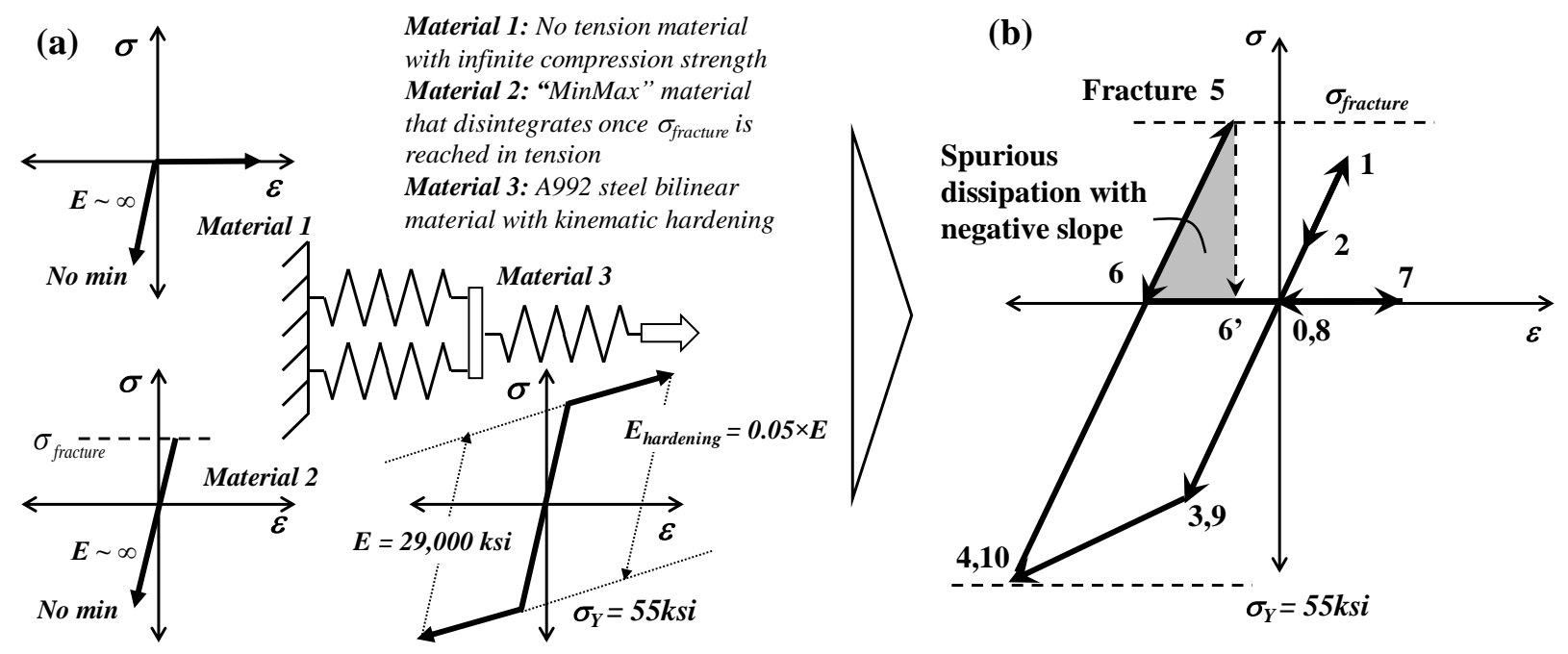

Figure 5: Constitutive material model for simulating fracture and post-fracture response: (a) Construction of model using series and parallel springs in OpenSEES, (b) Resultant response

Referring to Figure 3, each flange was represented as one fiber to reflect its instantaneous fracture consistent with experimental observations. The web was discretized into approximately 64 fibers, such that the model could simulate partial fracture of the splice (such as shown in Figure 4 previously). Several Engineering Demand Parameters (EDPs), and other phenomena were monitored during the simulations. Of these, three are most relevant to the objectives of this paper: (1) the interstory drift, as well as lateral displacement histories at every level, which are used as a general indicator of system response, as well as to infer collapse, (2) the vertical displacement history at the top of the frame, to record rocking after splice fracture, and (3) the stress and strain histories in all fibers at the splice locations, which are used to track the precise instant of fracture.

The next section discusses the framework within which the frame models were applied.

\section{Framework for Performance Assessment and Simulation Strategy}

Following the methodology discussed in the previous section, frame models were constructed in OpenSEES for both the 4- and the 20- story archetype frames. Two sets of analyses were conducted for each of the frames: (1) Analyses that do not simulate fracture of the splices - in 
269 effect setting the quantity $\sigma_{\text {fracture }}=\infty$ for all splices; these are denoted $\mathrm{N}$ and (2) Analyses that 270 reflect splice fracture as per the constitutive model discussed in the previous section, which are 271 denoted F.

272 Each of these analysis sets includes a suite of NLTHA simulations conducted using "Cloud 273 Analysis" (Jalayer, 2003), which is based on simple regression in the logarithmic space of 274 structural response (from NLTHA) versus seismic intensity for a set of recorded ground motions. 275 Hence, to determine the statistical properties of the cloud response (Jalayer and Cornell, 2009), the 276 linear least squares is applied on EDPs versus Intensity Measures (IMs) for a suite of ground 277 motion (unscaled) in order to estimate the conditional mean and standard deviation of EDP 278 given IM. The simple power-law model is used here:

$$
E D P=a I M^{b}
$$

280 where $a$ and $b$ are the parameters of the regression. The standard deviation $(s)$ of the regression is 281 assumed to be constant with respect to IM over the range of IMs in the cloud. The power-law 282 model illustrated in Equation (2) can be simply re-written as shown below in Equation (3) as a 283 linear expression of the natural logarithm of the EDP and the natural logarithm of the IM:

$$
\ln (E D P)=\ln (a)+b \ln (I M)
$$

285 The use of logarithmic transformation indicates that the EDPs are assumed to be conditionally 286 lognormally distributed (conditional upon the values of the IMs); this is a common assumption 287 that has been confirmed as reasonable in many past studies.

288 Unscaled ground motion records from the SIMBAD (Selected Input Motions for displacement289 Based Assessment and Design) database (Smerzini et al., 2014), were used as input for the cloud 
analysis. SIMBAD includes 467 tri-axial accelerograms, consisting of two horizontal (X-Y) and one vertical (Z) components, generated by 130 worldwide seismic events (including main shocks and aftershocks). These accelerograms were assembled from various ground motion databases derived for different regions of the world. In particular, the database includes shallow crustal earthquakes with moment magnitudes (M) ranging from 5 to 7.3 and epicentral distances $\mathrm{R} \leq$ $35 \mathrm{~km}$. This provides strong ground motion records of engineering relevance for most of the design conditions of interest without introducing large scaling factors. From this suite, a subset of 100 ground motion records was considered to provide a statistically significant number of strongmotion records of engineering relevance for the applications of this study. These records were selected for each building characterized by its $T_{1}$, by first ranking the 467 records in terms of their $\mathrm{S}_{\mathrm{a}}\left(\mathrm{T}_{1}\right)$ values (by using the geometric mean of the two horizontal components) and then keeping the component with the largest $S_{a}\left(T_{1}\right)$ value (for the 100 stations with highest mean $S_{a}\left(T_{1}\right)$ ). Spectral acceleration at the structure's fundamental period, $\mathrm{S}_{\mathrm{a}}\left(\mathrm{T}_{1}\right)$, was selected as the IM for this study. Results of the cloud analysis for the $\mathrm{N}$ and $\mathrm{F}$ analysis sets are now discussed.

\section{Results of cloud simulations for Non-Fracture (N) runs}

Referring to prior discussion, one set of cloud simulations was conducted for both the 4- and 20story frames, albeit without simulation of splice fracture. These provide an assessment of the "ideal" response, assuming all splices are strong enough to resist fracture. This may be considered indicative of a building that has been fully retrofitted (e.g., with CJP welds) to mitigate splice fracture. These simulations represent building performance perfectly prior to fracture of the first splice. As a result, they may be conservatively interpreted for assessing loss of building performance, assuming that fracture of the first splice will trigger system instability; the conservatism inherent in this type of assessment is a major motivator for this study. Figures $6 a$ and 
$313 \mathrm{~b}$ below show scatter plots (triangular markers) of maximum interstory drift ratio (MIDR) versus

314 the selected IM, i.e., $\mathrm{S}_{\mathrm{a}}\left(\mathrm{T}_{1}\right)$ for the 4- and 20- story frames respectively, as generated from the

315 cloud simulations (conduced as per the methodology discussed previously). Also indicated on the

316 plot are corresponding scatter points from the cloud analyses $(F)$ that simulate splice fracture; these

317 are discussed later. Each of the scatter plots identifies important levels of IM; these are: (1) The

318 design level (10\% probability of exceedance in 50 years) $\mathrm{S}_{\mathrm{a}}\left(\mathrm{T}_{1}\right)^{10 / 50}$ corresponding to the building

319 design parameters discussed earlier (Los Angeles, on stiff soil), (2) $S_{a}\left(T_{1}\right)^{2 / 50}$ corresponding to the

320 Maximum Considered Event (2\% probability of exceedance in 50 years), and (2) the lowest

$321 \mathrm{~S}_{\mathrm{a}}\left(\mathrm{T}_{1}\right)^{\text {First-fracture }}$ at which the stress demand in any splice flange exceeds its capacity, as determined

322 by Equation (1). This $S_{a}\left(T_{1}\right)$ corresponds to the lowest intensity at which fracture was observed

323 during the (F) simulations. The hollow triangles represent runs during which the capacity of at

324 least one splice was exceeded, implying that the $(\mathrm{N})$ simulations are unsatisfactory for these runs,

325 since they cannot simulate post-fracture response of the frames. Referring to Figures $6 \mathrm{a}$ and $\mathrm{b}$, the

326 following observations may be made:

1. As expected, for both buildings, response is identical from the $\mathrm{N}$ and $\mathrm{F}$ runs when no fracture is observed (i.e., below $S_{a}\left(T_{1}\right)^{\text {First-fracture }}$ ).
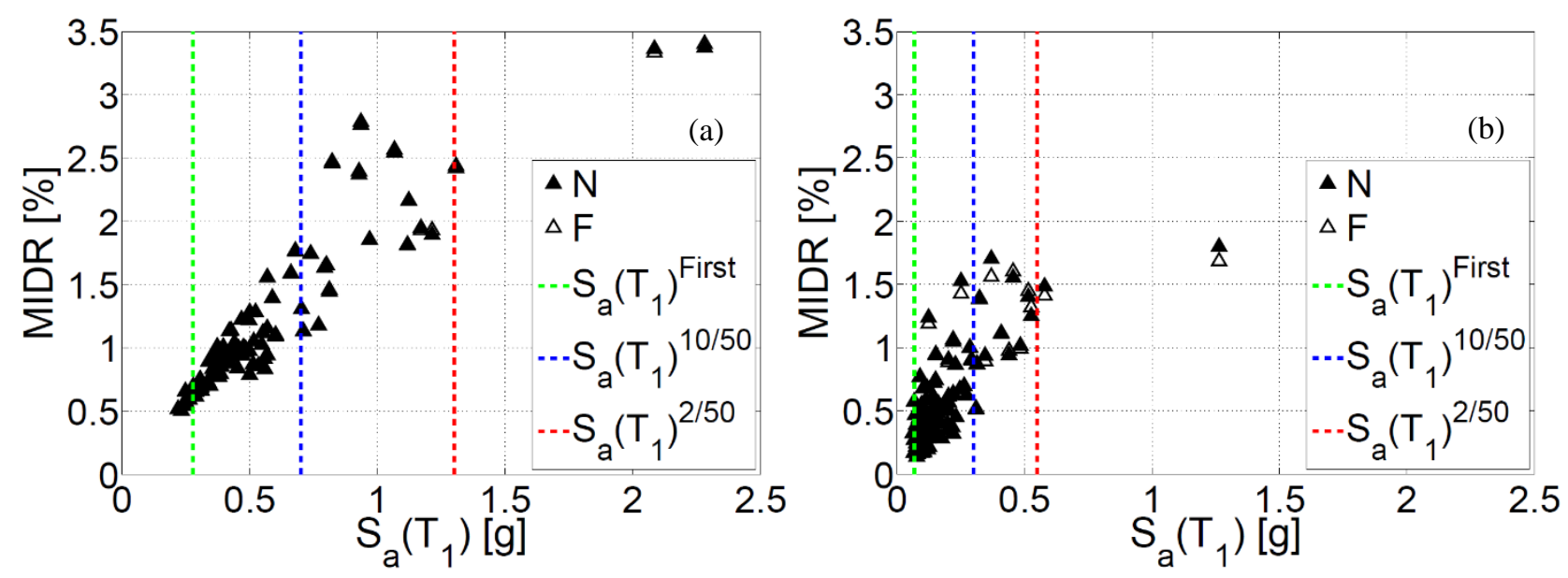

Figure 6: Maximum interstory drift ratio versus ground motion intensity (spectral acceleration) for (a) 4-story frame, and (b) 20-story frame 
2. Collapse is not observed in any of the cases (for either of the buildings). Referring to the figure, it is noted that most of the ground motions used have $S_{a}\left(T_{1}\right)$ values less than the 2/50 IM level. For a well-designed building, absence of collapse at this level is not surprising. In fact, this is in agreement with Incremental Dynamic Analysis (IDA; -Vamvatsikos and Cornell, 2002)) previously conducted for the same buildings by the authors (Galasso et al., 2015), as well with results of NLRHA simulations on the same buildings by others (Shen et al., 2010).

3. The IM level $S_{a}\left(T_{1}\right)^{\text {First-fracture }}$ corresponds to about a $45 / 50$ probability of exceedance for the 20 -story building (i.e., about 87 year return period). For the 4 -story building, $S_{a}\left(T_{1}\right)^{\text {First-fracture }}$ corresponds to about a $75 / 50$ probability of exceedance for the 20 -story building (i.e., about 35 year return period). These values are relatively similar to those determined previously by Galasso et al., (2015) through IDA and suggest that the first splice fracture occurs with an unacceptably high likelihood.

Point 3 above, when considered together with Figure 6a and b indicates that: (1) for a large range of IM (hazard) levels, analysis that do not simulate splice fracture are invalid, unless it is assumed that splice fracture in itself is an indicator of loss of building performance/collapse, and (2) if this assumption is made, then the resultant probabilities (or return periods) are unacceptably high, essentially requiring complete retrofit of all splices. This motivates the next set of cloud analyses.

\section{Results of cloud simulations for runs simulating splice fracture (F)}

Referring to the discussion above, if loss of building safety is assessed solely based on the first splice fracture, the implications are unacceptable. Consequently, the Cloud Analysis was repeated for both frames, including the simulation of splice fracture as per the process summarized earlier, to examine building response after splices begin to fracture. For this set of simulations, each fiber within the spliced section was assigned the constitutive model schematically illustrated in Figure 
352 5. Figure 6a and $b$ (which plot the $S_{a}\left(T_{1}\right)$ against peak interstory drift) also show scatter points

353 from the (F) simulations - these are the hollow triangles. Comparing the point clouds from the (N)

354 and the $(\mathrm{F})$ simulations, the following points may be made:

355 1. As previously observed, until the first splice fractures (indicated by the vertical line 356 corresponding to $\left.\mathrm{S}_{\mathrm{a}}\left(\mathrm{T}_{1}\right)^{\text {First-fracture }}\right)$, the response from both simulations are coincident as 357 expected.

2. For stronger motions (i.e., those with a higher $S_{a}\left(T_{1}\right)$, the response of the $(F)$ simulations deviates from the $(\mathrm{N})$ simulations, such that on average, the interstory drift is less than $1 \%$ for the 4 -story and about $2 \%$ for the 20 -story lower as compared to the interstory drift for the same

3. The above observation is counterintuitive, suggesting that in terms of interstory drift, the splice fractures improve structural performance, rather than exacerbate it. To explain this response, a closer investigation of the underlying physics is warranted. Figures $7 \mathrm{a}-\mathrm{b}$, and Figures $8 \mathrm{a}-\mathrm{b}$ provide such an examination. For illustrative purposes, Figures $7 \mathrm{a}$ and $\mathrm{b}$ illustrate the time history of the vertical displacement of a roof node at an exterior column for the 4- and 20- story frames respectively, for both the $(\mathrm{N})$ and $(\mathrm{F})$ analyses. The time history corresponds to one representative ground motion for each of the frames (i.e., corresponding to an IM level consistent with MCE for the 4-story frame and to the maximum IM level in the database for the 20-story frame); responses for all other ground motions in which splices fracture are qualitatively similar. Figures $7 \mathrm{a}$ and $\mathrm{b}$ indicate response for both the $(\mathrm{F})$ and $(\mathrm{N})$ analyses corresponding to this ground motion. Referring to the figure, it is observed that immediately after the first splice fractures (which is also indicated in the time histories), the vertical 
375 displacements of the $(\mathrm{F})$ simulations immediately deviate from the $(\mathrm{N})$ simulations, indicating 376 the onset of rocking deformations in the portion of the frame above the splice fracture. As more 377 splices fracture, the rocking deformations increase. It is well known (Housner, 1963; Makris, 378 2014) that building rocking may be extremely beneficial to structural response, by mobilizing 379 the rotational inertia of the rocking body. In fact, various researchers have recommended 380 allowing such rocking to enhance structural performance - these solutions include systems 381 with uplifting bases (Eatherton et al., 2014; Huckelbridge and Clough, 1978), as well as those 382 that feature columns with no tension capacity (Wada et al., 2001), resulting in behaviour very 383 similar to that observed after splice fracture in this study. In each case, experiments as well as 384 simulations have indicated an improvement in response. When considered cumulatively, this 385 research suggests that the observed reduction in frame drifts due to splice fracture is less $386 \quad$ surprising. 

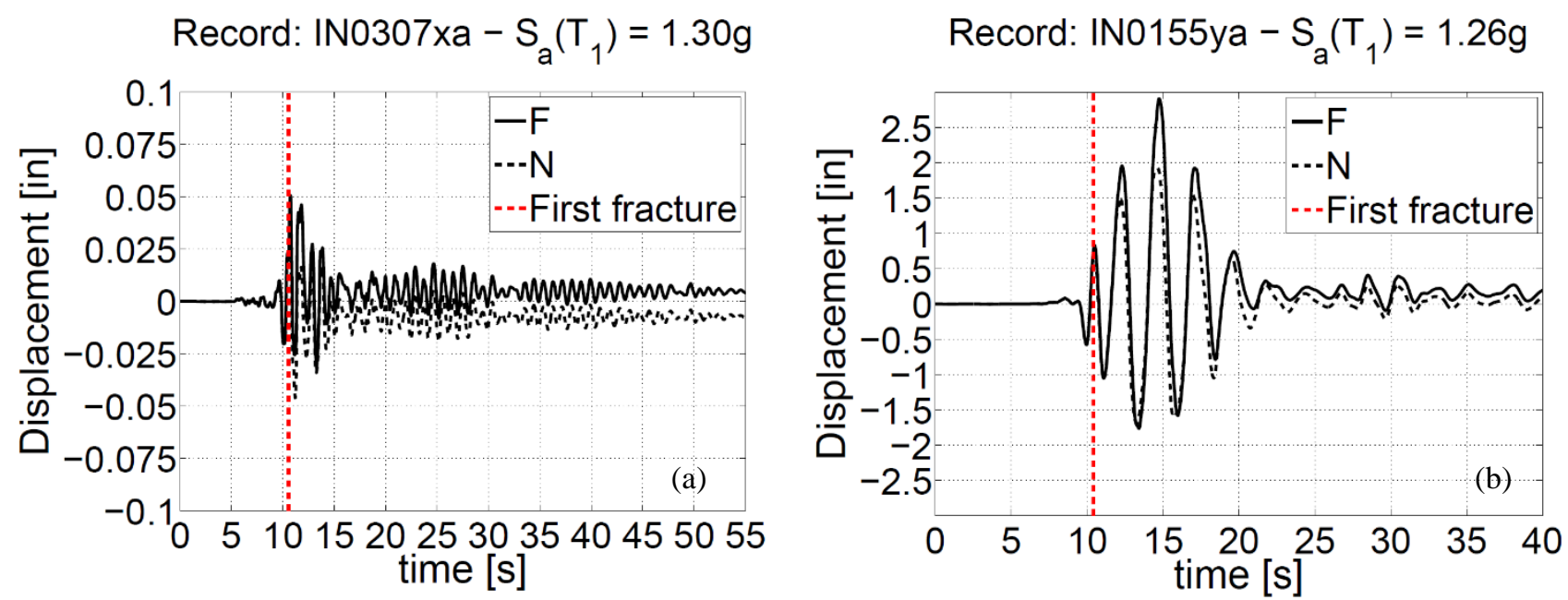

Figure 7: Representative time histories of vertical displacement at top story of exterior column for (a) 4-story frame, and (b) 20-story frame

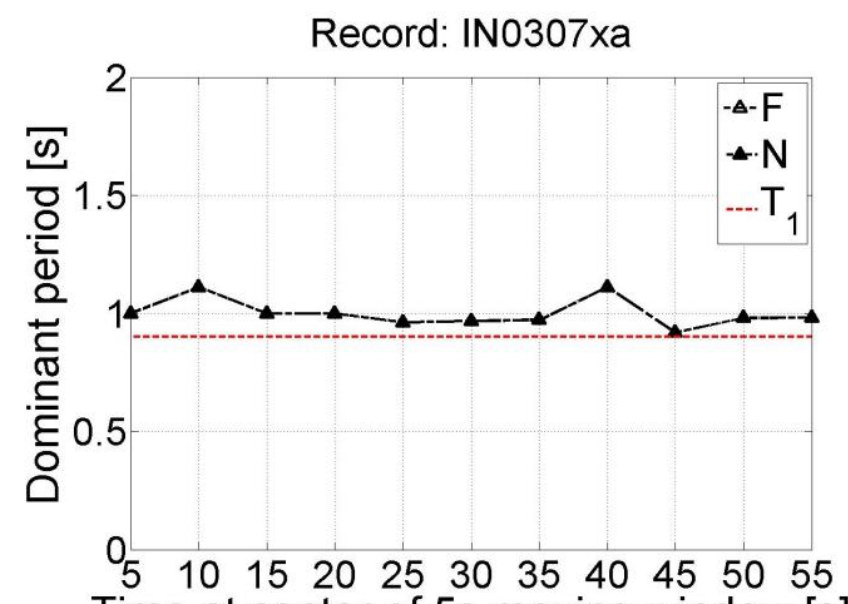

Time at center of $5 \mathrm{~s}$ moving window [s]

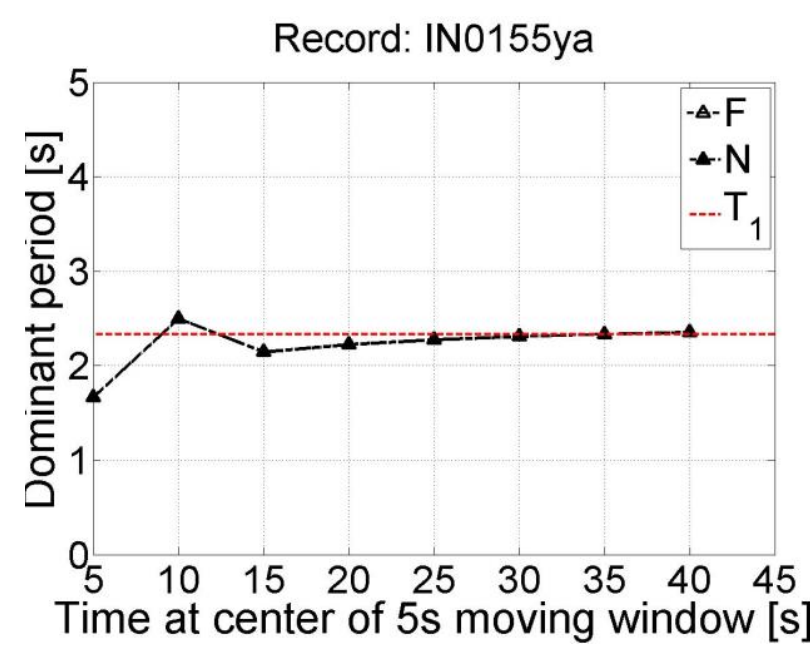

Figure 8: Representative evolution of dominant structural period for (a) 4-story frame, and (b) 20-story frame

391 Using the ground motions selected for Figures 7a and b, above, Figures $8 \mathrm{a}$ and $\mathrm{b}$ plot the evolution

392 in frame dynamic characteristics (specifically, the dominant period) over the duration of the 393 ground motion. This is accomplished by generating a moving window Fourier transform of the 394 lateral roof displacement history for each of the ground motions, and recovering the peak or 395 dominant period. Figures $8 \mathrm{a}$ and $\mathrm{b}$ show this evolution for both the $(\mathrm{N})$ and $(\mathrm{F})$ simulations, for 396 both the 4- and 20 story buildings. Referring to the figure, the dominant dynamic frequency of 397 either frame does not change appreciably (less than 10\%) over the duration of the motion. It is 
worth noting that over this duration, 2 splices fractured for the ground motion shown for the 4-

399 story building, whereas 13 splices fractured for the 20-story building. The relatively modest

400 increase in building period after splice fracture may be attributed to the following factors: (1) the

401 building resists force primarily through a shear mode, such that the loss of splices and associated

402 overturning response does not affect dynamic characteristics, and (2) the splices are dominated

403 (for most of the time history) by compressive forces, due to the presence of gravity loads. Under

404 these conditions, the splices are fully functional and able to carry load. When considered along

405 with Figures $7 \mathrm{a}$ and $\mathrm{b}$, this suggests that the improved performance may be attributed to rocking 406 (and associated mobilization of rotational inertia), rather than any isolation effect due to period 407 elongation.

408 In summary, the $(\mathrm{F})$ simulations suggest that due to the transition of structural response to a rocking 409 dominated mode, the fracture of splices has a positive effect on structural performance, if interstory 410 drift is considered as its primary indicator. While the above discussion summarizes the net effect 411 of splice fracture on key aspects of structural response, the phenomenology of splice fracture is 412 interesting in itself, and may be used for more refined insights into post-fracture response, with 413 possible implications for generalization of findings. To develop this understanding, the instants of 414 individual splice flange fractures were monitored during each of the time histories in the (F) cloud 415 analyses. More specifically, the initiation of fracture (i.e., triggering the critical stress as shown in 416 Figure 5b earlier) was monitored at each flange within each splice, during all ground motions in 417 the cloud analysis. In some splices, both flanges fractured instantaneously, whereas in others one 418 flange and part of the web (i.e., fibers corresponding to this portion of the cross-section) fractured. 419 Both cases are considered in the fracture pattern analysis presented in Figure 9a-e. Once 
aggregated, information regarding the instants of splice fracture may be synthesized to develop several observations regarding the phenomenology of splice fracture:

422 1. In the 4-story frame, there is only one spliced level (see Figure 2). During all ground motions 423 in which fracture was observed, only the splices in the exterior columns fractured, with the 424 interior columns splices remaining intact. Thus, no more than two splices fractured in any 425 ground motion.

2. Figures 9a-e depict the phenomenology of splice fracture in the 20-story building, which is not

427 quite as straightforward. In Figure 9a, the number indicated adjacent to each splice location indicates the fraction of ground motions (out of all ground motions that caused any splice

3. Referring to Figure 9a, it is immediately apparent that splices 7 and 12 (exterior columns on the $5^{\text {th }}$ story are most likely to fracture), such that they fracture in $\sim 84 \%$ of ground motions that cause fracture. This is closely followed by splices 13 and 18 (also in the exterior columns) in the $8^{\text {th }}$ story. Fracture at these locations is evidently controlled by overturning actions, which

4. In terms of fracture probability, the next group of splices is in the higher stories of the frame (i.e., splices $25-30$ in the $14^{\text {th }}$ story). Interestingly, for the higher stories, the interior columns 

tension in the columns due to overturning, as well as flexure.
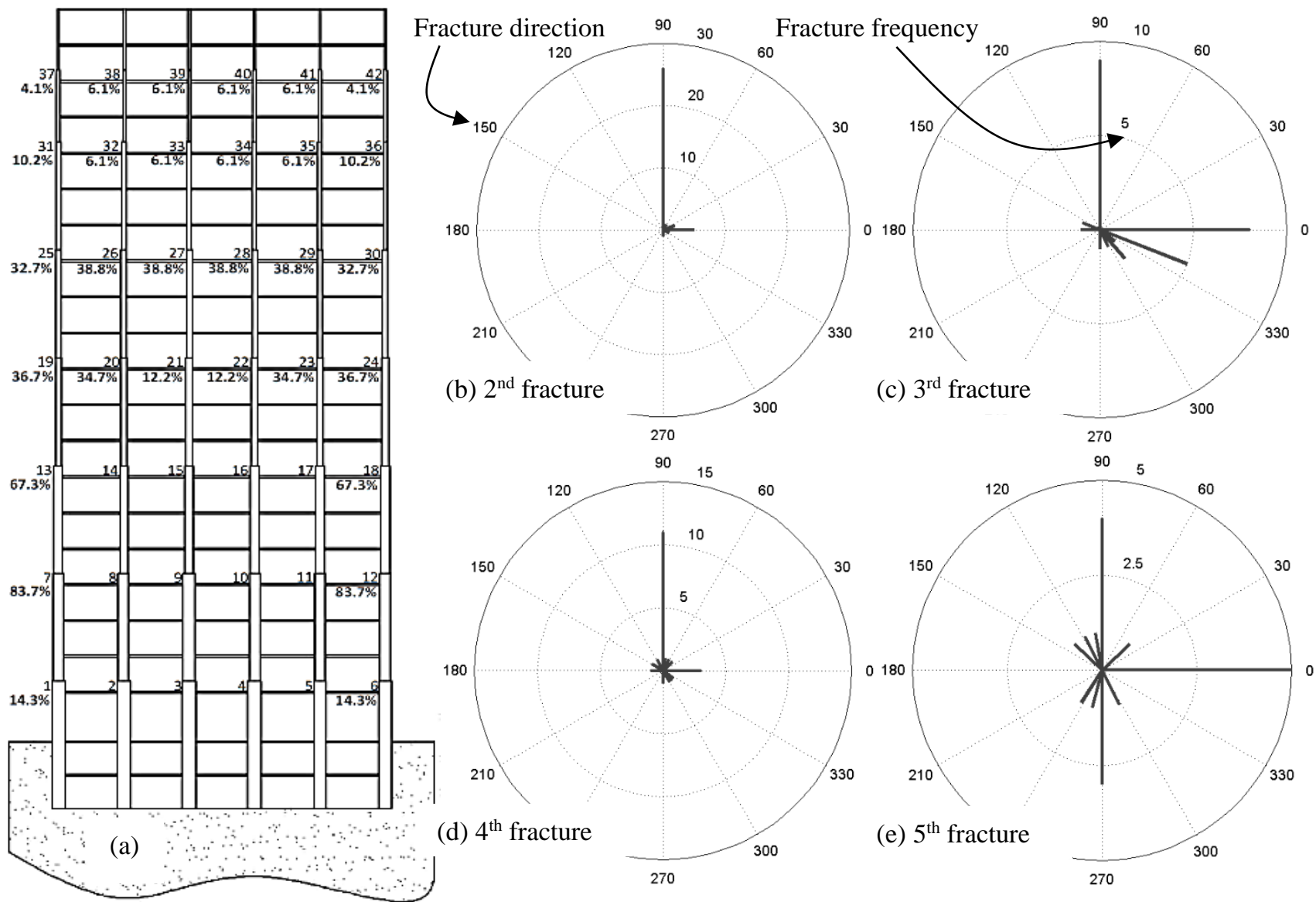

Figure 9: Fracture patterns in 20-story frame (a) Fracture likelihood at each splice, and (b)-(e) Polar histograms indicating directions of fracture propagation from splice to splice

445 The above observations provide a general sense of splices that are most vulnerable, suggesting that

446 fractures begin in the exterior splices of lower stories, and propagate upwards and inwards.

447 However, this observation about the temporal propagation is conjecture, since only aggregate

448 probabilities are shown in Figure 9a, without information about the propagation of fracture from

449 one splice to the next. To this end, Figures 9b-e illustrate polar histograms of fracture, which 450 represent the "propagation directions" of splice fractures for each ground motion, and represent

451 the vector direction from the $i^{\text {th }}$ to the $i+1^{\text {th }}$ splice fracture. For example, positive 90 degrees on 
452 the polar histogram indicates that the $i+1^{\text {th }}$ splice fracture was directly above the $i^{\text {th }}$ fracture, 453 whereas 0 degrees indicates that it was directly to the right. Figures $9 \mathrm{~b}-\mathrm{e}$ show this information for 454 the $2^{\text {nd }}, 3^{\text {rd }}, 4^{\text {th }}$, and $5^{\text {th }}$ splice fractures respectively. A corresponding figure is not shown for the 455 4-story frame, since only two splices fracture. With this background, an examination of Figures $4569 \mathrm{~b}-\mathrm{e}$ reveals the following:

457 1. Referring to Figure $9 b$, a large majority of the $2^{\text {nd }}$ fractures show an angle of 90 degrees, i.e., 458 upwards. This is interesting, in that it represents that rather than propagating across a story, the 459 fractures propagate upwards through a column. Recall that the first fractures are predominantly 460 in the exterior columns in the lower stories. Interior columns in these stories have significantly 461 lower axial tension, as well as greater compression due to gravity; this may explain the 462 tendency of fracture to initially propagate upwards. From a behavioral standpoint, this type of 463 fracture propagation (as opposed to one that would sever a story) possibly results in a greater 464 retention of base shear capacity, such that structural performance is not severely compromised, 465 as shown previously in Figures $6 a$ and $b$.

466 2. As shown in Figures 9c-e, subsequent fractures are less consistent in their direction of 467 propagation, possibly because as the fractures move to higher stories, interior column splices 468 become more prone to fracture as well, as discussed earlier.

469 In summary, Figures 9a-e (i.e., the fracture percentages and the polar histograms) suggest a general 470 pattern of splice fracture. In broad terms, fractures begin in the lower exterior columns then move 471 upwards, and inwards in the higher stories. There is no observed tendency for fractures to 472 propagate horizontally severing a story. When considered along with the previous observations 473 regarding the beneficial effects of frame rocking, and the ability of splices to carry compression 
474 even after fracture, this may well explain the satisfactory performance of the building even with 475 splice fracture.

476 It is important to recall here that the $(\mathrm{F})$ simulations only examine the response of intact or

477 undamaged buildings with respect to splice fractures. However, referring to Figures $5 \mathrm{a}$ and $\mathrm{b}$ and 478 associated discussion, it is highly likely that frames undergo fracture at hazard levels significantly 479 below design level, with the implication that several splice fractures may already be present in 480 existing buildings. The effect of these pre-existing fractures merits future examination.

\section{SUMMARY AND CONCLUSIONS}

482 This study examines the effect of Welded Column Splice fracture on the seismic response of Steel 483 Moment Resisting Frames (SMRFs). The primary motivation for this paper is pre-Northridge 484 welded column splice details with large crack like flaws that arise at the root of Partial Joint 485 Penetration (PJP) welds. Previous research has shown these details to be highly susceptible to 486 fracture. When analyzed within a Performance Based Earthquake Engineering (PBEE) framework, 487 this susceptibility results in unacceptably high probabilities of splice fracture over the life of the 488 building. Further, splices in many buildings from the pre-Northridge era have not been retrofitted; 489 the post-Northridge retrofits have focused mainly on welded beam to column connections. The 490 implication is that WCSs may well be a weak link in building safety and performance. Retrofitting 491 splices in operational buildings is costly and challenging, and typically involves replacing the 492 entire PJP weld with a Complete Joint Penetration (CJP) weld. However, such a strategy is 493 predicated on the assumption that splice fracture will necessarily trigger building failure. In 494 addition to being possibly conservative, this assumption is simplistic and consistent with building 495 performance assessment based on component response (the state of the art in the 1990s) in contrast 496 to comprehensive system-based performance assessment, which is currently prevalent. Against 
497 this backdrop, this study examines the seismic response of two SMRFs (4- and 20- story) including

498 the effects of splice fracture within a modern PBEE framework.

499 The response is examined through a series of "cloud" analyses of the frames, where each cloud 500 analysis includes Nonlinear Response History Analysis of the frame models subjected to 100 501 ground motions. This procedure allows for an examination of frame response across a range of 502 ground motions as well as seismic intensities. When combined with local hazards, these analyses 503 may be used for risk assessment of various aspects of structural response such as peak 504 deformations, splice fracture, and collapse. The frame models simulate key aspects of structural 505 response such as geometric and material nonlinearity, and finite joint size. Most importantly from 506 the perspective of this study, the models are able to simulate tension fracture of the splice. The 507 modeling methodology relies on previous experimental, computational, and analytical research on 508 splices such that both the stress that triggers splice fracture, as well as subsequent cyclic response 509 are suitably simulated.

510 Two sets of cloud analyses are conducted. The first set examines frames with splices that do not 511 fracture, representing the performance of fully retrofitted splices. The second set examines initially 512 intact frames with simulated fracture; these represent unretrofitted frames that have not 513 experienced a damaging earthquake.

514 The primary finding of the cloud simulations is that splice fracture may not exacerbate structural 515 response or trigger collapse. In fact, splice fracture mobilizes rocking motions in the frame, 516 engaging the rotational inertia of the building above the fractured splice. This rocking reduces 517 structural deformations, possibly increasing the margin of safety against collapse. This type of 518 rocking-induced performance enhancement is well studied in literature, to the point that research 
519 has specifically examined tension-gapping columns as response mitigation mechanism (Wada et

520 al., 2001). A closer examination of the fracture patterns indicates that the fractures usually

521 originate in the exterior columns of the lower stories. For the 20 story frame, the primary tendency

522 is for the fractures to propagate upwards through a column, rather than sideways across a story.

523 The absence of story-severing fractures may additionally explain the satisfactory performance

524 observed despite the splice fractures. Subsequent (less frequent fractures) in higher stories tend to 525 be distributed more uniformly through the story, rather than just in the exterior columns.

526 Although the general finding is that for the considered frames, splice fracture is not significantly

527 detrimental to performance, this must be interpreted very cautiously against the limitations of the

528 study, which are numerous. From a methodological perspective, the main issue is that only two

529 buildings are studied. Although these are fairly generic in their floorplan and frame configuration,

530 deviations from these structural forms will result in behavior dissimilar to that reported in this

531 study. Also from a methodological perspective, the limitations of cloud analysis (e.g. assuming

532 the dispersion in response to be a constant at all IM levels) may be questioned. However, the

533 general trends in response are strong (and similar to those researched previously through

534 Incremental Dynamic Analysis of the same frames -(Galasso et al., 2015)), suggesting that this

535 limitation is not serious. Other methodological assumptions including simulating the building

536 response, including splice fracture as deterministic, such that the only variability is in the ground

537 motions. However, in the context of establishing baseline behavioral trends, this assumption is

538 reasonable.

539 From a modeling perspective, some issues must be noted as well. Chiefly, the splices simulate 540 tension fracture of the flange and web material. As a result, the post fracture response can simulate 541 axial gapping (separation) of the column, as well as flexural loss of strength. However, it cannot 
542 directly simulate the loss of shear strength at the splice, although it does reduce the lateral stiffness

543 of the columns due to introduction of the hinge within the column. The influence of this limitation

544 on simulated response may be interpreted as follows: (1) when the splice does not fracture

545 completely (as is the case in several splices), the modeling assumptions are valid, (2) in cases

546 where the splice is completely severed, then the simulations in this study may yield unconservative

547 insights (simulated performance better than true performance) especially if the remainder of the

548 structure is not sufficiently redundant; even in this case it is worth noting that the splices carry

549 shear in compression, and (3) if relative shear deformations are restricted at splices (through details

550 as such as full depth web plates welded to one of the connected columns) then response similar to

551 that observed in this study is possible. Modeling the loss of shear capacity due to tension fracture

552 is challenging within the constraints of frame-element based simulation. Recognizing this, 553 upcoming modeling guidelines for performance assessment of existing buildings (ATC 114 - n.d.)

554 propose a modeling approach similar in intent to the one used here. Other modeling limitations 555 include the use of 2-dimensional frame simulation, versus 3-dimensional building simulation, and 556 the use of only unidirectional (horizontal) ground motions, rather than 3-dimensional motions 557 including vertical accelerations. In summary, while the study reveals beneficial response modes 558 and behavioral trends, the results must be cautiously interpreted against all these limitations.

559 Finally, from a practical standpoint, this study suggests that full retrofit of the splices (i.e. 560 replacement of PJP with CJP welds) may not always be necessary, as a rule, and the NLRHA 561 conducted within a rigorous, probabilistic framework may respond beneficial response modes that 562 mitigate risk. In fact, such analyses may reveal contrary results; for the frames studied herein, the 563 simulations representing the retrofitted frames showed higher deformations. The analyses also 564 suggest considering other retrofit strategies that may be more economical than complete weld 
565 replacement. These may include details that restrain unseating or loss of shear capacity of the

566 column e.g., through guiding plates on the flanges or a bolted web plate. From a scientific

567 standpoint, the approach for modeling post-fracture response of fibers (through the constructed

568 constitutive model - Figure 5) may be considered a contribution. In closing, it is emphasized that

569 the main value of the study is not in the actual results of the NLRHA, which are somewhat specific

570 to the considered buildings, and limited by modeling assumptions. Rather, the study indicates that

571 NLRHA (if conducted within a sophisticated modeling framework), may suggest counterintuitive

572 response, and strategies for risk mitigation, which may or may not include retrofit, based on a

573 refined consideration of tradeoffs.

574

575 REFERENCES

576 1. AISC, 2010. AISC 341-10: Seismic Provisions for Structural Steel Buildings, AISC 341-10.

577 ed. American Institute of Steel Construction, Chicago, IL, USA.

578 2. Anderson, T.L., 1995. Fracture mechanics, 2nd Ed., 2nd ed. CRC Press, Boca Raton, FL.

579 3. Applied Technology Council, 2012. FEMA P-58, Seismic Performance Assessment of

580 Buildings, Volume 3 - Supporting Electronic Materials and Background Documentation (No.

581 FEMA P-58-3). Federal Emergency Management Agency, Washington (DC), USA.

582 4. Applied Technology Council, 2006. FEMA-445: Next-generation performance-based

583 seismic design guidelines (No. FEMA-445). Federal Emergency Management Agency,

$584 \quad$ Washington (DC), USA.

585 5. Applied Technology Council, 1997. FEMA P-273: NEHRP guidelines for the seismic 586 rehabilitatin of buildings (No. FEMA P-273). National Institute of Building Sciences, $587 \quad$ Washington (DC), USA. 
6. ASCE, 2006. ASCE/SEI 41-06: Seismic Rehabilitation of Existing Buildings, ASCE/SEI 4106. ed. American Society of Civil Engineers.

7. ASCE, 2005. ASCE/SEI 7-05: Minimum Design Loads for Buildings and Other Structures, ASCE/SEI 7-05. ed. American Society of Civil Engineers.

592 8. ATC, n.d. (Active Project). Development of Accurate Models and Efficient Simulation 593 Capabilities for Collapse Analysis to Support Implementation of Performance Based Seismic 594 Engineering (No. ATC-114). Applied Technology Council.

595 9. Barsom, J.M., 1975. Development of the AASHTO fracture-toughness requirements for 596 bridge steels. Eng. Fract. Mech. 7, 605-618.

597 10. Bruneau, M., Mahin, S.A., 1991. Full-scale tests of butt-welded splices in heavy-rolled steel 598 sections subjected to primary tensile stresses. Eng. J. Am. Inst. Steel Constr. 28, 1-17.

599 11. Chi, W., Deierlein, G.G., Ingraffea, A., 2000. Fracture toughness demands in welded beam600 column moment connections. J. Struct. Eng. 126, 88-97.

601 12. CUREe (Ed.), 1995. Directory of Northridge Earthquake Research. Berkeley, CA.

602 13. Eatherton, M., Ma, X., Krawinkler, H., Mar, D., Billington, S., Hajjar, J., Deierlein, G., 2014. 603 Design Concepts for Controlled Rocking of Self-Centering Steel-Braced Frames. Des.

604 Concepts Control. Rocking Self-Centering Steel-Braced Fram. 140.

605 doi:10.1061/(ASCE)ST.1943-541X.0001047

606 14. Galasso, C., Stillmaker, K., Eltit, C., Kanvinde, A.M., 2015. Probabilistic demand and 607 fragility assessment of welded column splices in steel moment frames. Earthq. Eng. Struct. 608 Dyn. 44. 
15. Gupta, A., Krawinkler, H., 1999. Seismic demands for performance evaluation of steel moment resisting frame structures (SAC Task 5.4.3) (No. Blume Center Technical Report \#132), Blume Center Technical Report \#132. Stanford University, Stanford, CA, USA.

16. Housner, G., 1963. The Behavior of Inverted Pendulum Structures During Earthquakes. Bull. Seismol. Soc. Am. 53, 403-417.

17. Huckelbridge, A., Clough, R., 1978. Seismic Response of Uplifting Buildng Frame. J. Struct. Div. 104, 1211-1229.

18. Jalayer, F., Cornell, C.A., 2009. Alternative nonlinear demand estimation methods for probability-based seismic assessments. Earthq. Eng. Struct. Dyn. 38, 951-972. doi:10.1002/eqe.876

19. Kanvinde, A.M., Deierlein, G.G., 2004. Prediction of Ductile Fracture in Steel Moment Connections During Earthquakes Using Micromechanical Fracture Models. Presented at the 13th World Conference on Earthquake Engineering, International Association for Earthquake Engineering, Tokyo, Japan.

20. LATBC, 2014. An alternative procedure for seismic analysis and design of tall buildings located in the Los Angeles region. Los Angeles Tall Building Council, Los Angeles, CA, USA.

21. Makris, N., 2014. A half-century of rocking isolation. Earthq. Struct. 7, 1187-1221.

22. Mazzoni, S., McKenna, F., Scott, M.H., Fenves, G.L., 2009. Open system for earthquake engineering simulation user command- language manual, OpenSees version 2.0. University of California, Berkeley, Berkeley, CA.

23. Nudel, A., Marusich, S., Dana, M., Roufegarinejad, A., 2015. Evaluation and Remediation of Pre-Northridge Steel Moment Frame Column Splices, in: Improving the Seismic 
Performance of Existing Buildings and Other Structures 2015. Presented at the Second ATC \& SEI Conference on Improving the Seismic Performance of Existing Buildings and Other Structures, American Society of Civil Engineers, Reston, Virginia, pp. 287-302.

24. Nuttayasakul, N., 2000. Finite element fracture mechanics study of partial penetration welded splice (PhD Thesis). Stanford University, Stanford, CA, USA.

25. Ricles, J.M., Zhang, X., Lu, L., Fisher, J., 2004. Development of seismic guidelines for deepcolumn steel moment connections, ATLSS Report No. 04-13. ATLSS, Bethlehem, PA.

26. SAC Joint Venture, 1996. Selected results from the SAC phase 1 beam-column connection pre-test analyses (No. Technical Report 96-01), Technical Report 96-01. SAC Joint Venture, Sacramento, CA, USA.

27. SAC Joint Venture, 1995. Analytical and field investigations of buildings affected by the Northridge earthquake of January 17, 1994 (No. Technical Report 95-04), Technical Report 95-04.

28. Shaw, S.M., 2013. Seismic performance of partial joint penetration welds in special moment resisting frames (PhD Dissertation). University of California, Davis, Davis, CA, USA.

29. Shaw, S.M., Stillmaker, K., Kanvinde, A.M., 2015. Seismic response of partial-jointpenetration welded column splices in moment-resisting frames. Eng. J. Am. Inst. Steel Constr. 52, 87-108.

30. Shen, J., Sabol, T.A., Akbas, B., Sutchiewcharn, N., 2010. Seismic demand of column splices in special moment frames. Eng. J. Am. Inst. Steel Constr. 47, 223-240.

31. Smerzini, C., Galasso, C., Iervolino, I., Paolucci, R., 2014. Ground motion record selection based on broadband spectral compatibility. Earthq. Spectra 30, 1427-1448. 
654 32. Spacone, E., Filippou, F.C., Taucer, F.F., 1996. Fibre beam-column model for non-linear 655 analysis of F/C frames: part I. Formulation. Earthq. Eng. Struct. Dyn. 25, 711-725.

656 33. Stillmaker, K., Kanvinde, A.M., Galasso, C., 2016. Fracture mechanics based design of 657 column splices with partial joint penetration welds. ASCE J. Struct. Eng. 142.

658 34. Vamvatsikos, D., Cornell, C.A., 2002. Incremental dynamic analysis. Earthq. Eng. Struct.

$659 \quad$ Dyn. 31, 491-514. doi:10.1002/eqe.141

660 35. Wada, A., Yamada, S., Fukuta, O., Tanigawa, M., 2001. Passive controlled slender structures 661 having special devices at column connections. Presented at the 7th International Seminar on 662 Seismic Isolation, Passive Energy Dissipation and Active Control of Vibrations of Structures, 663 Italian National Association for Earthquake Engineering (ANIDIS), Rome, Italy.

664 36. Wu, S., Wang, X., 2010. Mesh Dependence and Nonlocal Regularization of One665 Dimensional Strain Softening Plasticity. J. Eng. Mech. 136, 1354-1365.

666 doi:10.1061/(ASCE)EM.1943-7889.0000184

667 